\title{
Effect of Joining Conditions on the Shear Strength of Barium Titanate Joint Brazed with Molten Aluminum
}

\author{
Ikuzo Goto*, Setsuo Aso and Ken-ichi Ohguchi \\ Department of Materials Science, Graduate School of Engineering Science, Akita University, Akita 010-8502, Japan
}

\begin{abstract}
The shear tests using barium titanate joint brazed with molten aluminum under several joining conditions were conducted to determine the optimum joining condition. The barium titanate joints brazed at $780^{\circ} \mathrm{C}$ had estimative strength, while those brazed at $720^{\circ} \mathrm{C}$ did not. The strengths of the joints brazed at $780^{\circ} \mathrm{C}$ became higher with increase in the heat holding time. Especially, the heat holding time for more than $24 \mathrm{~h}$ gave higher joint strength than the original shear strength of barium titanate. To discuss the bonding mechanism, the fractured surfaces of the joints were observed and the cross-sectional element distributions in the vicinity of the joint interface were investigated. The observations demonstrated that pieces and grains of the fractured barium titanate were strongly bonded to the aluminum layer at longer holding times. Meanwhile, from the oxygen distributions, relatively thick alumina layers that formed between barium titanate and aluminum at longer holding times were observed. These facts suggest that interfacial bonding is achieved through the formation of an alumina interlayer due to progressive oxidation of molten aluminum during joining process. [doi:10.2320/matertrans.L-M2017820]
\end{abstract}

(Received February 2, 2017; Accepted May 5, 2017; Published June 9, 2017)

Keywords: joining, pure metal, aluminum, ceramic, barium titanate

\section{Introduction}

Electric vehicles (EVs) have recently grown in popularity due to their lower petroleum use and $\mathrm{CO}_{2}$ emissions. However, EVs require on-board electric heaters because engine exhaust heat is not available. Ceramics with positive temperature coefficients (PTC), such as barium titanate (Ba$\mathrm{TiO}_{3}$ ), have been widely used for electric heating elements in EVs ${ }^{1)}$. Materials with PTC properties show greater electrical resistance with increasing temperature. The self-regulating function of such heating elements, which maintains a constant heating element temperature, provides excellent safety and energy conservation features ${ }^{1)}$. PTC ceramics are also used as auxiliary electric heaters for some gasoline-fueled vehicles. In EVs, electric heaters consume electricity from the vehicle power source, thereby reducing the mileage of the EVs when electric heaters are used. Therefore, heating efficiency is an important issue for EVs. For the conventional PTC heaters, the PTC ceramics are in contact with heat diffusers via layers of low thermal conductivity, such as insulating films and thermal grease. Although heated water or air is generally circulated inside the vehicles ${ }^{1)}$, thermal resistance is present and some energy loss occurs due to the temperature drop during heat transfer. To address this problem, directly bonded PTC ceramics with aluminum heat diffusers are a candidate structure for future PTC heaters. Aluminum has the advantages of higher thermal conductivity and thermal stress relaxation characteristics than aluminum alloys $^{2)}$. These candidate PTC heaters will enable longer the mileage for EVs as a result of their excellent heating efficiency.

Various conventional methods are available for joining ceramics with aluminum, such as diffusion, activation and metallization $^{3,4)}$. However, most of these methods involve high process costs and/or require some interlayers consisting of another materials ${ }^{3-5}$, which sometimes produce joining defects such as interfacial voids ${ }^{2}$. These problems can

*Corresponding author, E-mail: goto@gipc.akita-u.ac.jp be solved using cast-in insertion processes which also have greater flexibility in shape and size of the aluminum portions ${ }^{2,6,7)}$. The casting process method has already been used for the integral manufacture of directly bonded power module parts ${ }^{6,7)}$, consisting of an aluminum nitride substrate and an aluminum heat sink. These materials have not only excellent ability to remove heat from power devices but also sufficient reliability for use under cyclic thermal loading ${ }^{6,7)}$. Similarly, cast-in insertion may have applicability to the manufacture of directly bonded PTC heaters along with the formation of aluminum diffusers ${ }^{8}$.

For cast-in insertion processes, the main factors influencing the resulting joint strength of ceramics with metal include the wettability, surface roughness ${ }^{9)}$, temperature, pressure, holding time and atmosphere ${ }^{10-14)}$. These factors may affect interdiffusion, interfacial reactions and oxidation behavior, as well as the interfacial contact ${ }^{3,9-14)}$. In some cases, relatively higher joint strengths can be obtained under atmospheric conditions ${ }^{13)}$, which is a useful feature in industrial settings. However, the particular factors influencing the joint strength obtained by cast-in insertion of aluminum with Ba$\mathrm{TiO}_{3}$ have not been determined. In this study, the effects of joining conditions on the joint strength of $\mathrm{BaTiO}_{3}$ brazed by aluminum were investigated along with the joining mechanism.

\section{Experimental Methods}

As-sintered $\mathrm{BaTiO}_{3}$ tablets ( $>99.9 \%$ purity, Ra 0.8 surface roughness) and a aluminum plate (JIS A1050, $>99.5 \%$ purity, $1 \mathrm{~mm}$ thickness) were prepared for use as raw materials Several $\mathrm{BaTiO}_{3}$ tablets were ground to increase the surface roughness. These materials were cleaned with acetone. Figure 1(a) illustrates the preparation process of the joint specimens. The aluminum plate was melted by heating in an electric muffle furnace under atmospheric conditions, and then solidified by cooling at room temperature. A sand mold was made from silica sand and water glass by the $\mathrm{CO}_{2}$ process and coated with a boron nitride spray. Sand molds not only 
act to prevent the effects of thermal shock due to slow cooling, but they also exhibit suitable solidification characteristics for casting heat diffusers, which may potentially be applied for prototyping of candidate PTC heaters ${ }^{15,16)}$. The sand mold contained an outflow space for the molten aluminum, and the outflowed portion of the solidified aluminum was removed by grinding. Following this procedure, joint specimens were produced using variations in the joining conditions such as surface roughness, joining temperature (in the furnace), pressure (weight) and holding time (time in the furnace). The joining conditions employed in this study are shown in Table 1.

The aluminum layer thickness of the specimens was calculated based on the thickness difference between the specimen total height and twice the average height of the $\mathrm{BaTiO}_{3}$ tablets, which were measured using a micrometer. Next, the joint strength of each specimen was evaluated in a shear test, as shown in Fig. 1(b ${ }^{17)}$. This test was conducted using a universal testing machine and jigs at a testing rate of $1 \mathrm{~mm} \cdot \mathrm{min}^{-1}$. The shear strength was calculated from the maximum load during the test. The joint shear strength is an important factor to consider in PTC heaters, because of difference of the thermal expansion that could occur in use ${ }^{14)}$. The fracture surface of the specimens after the tests were observed using an optical microscope and a scanning electron microscope (SEM). Prior to testing, several specimens were (a)

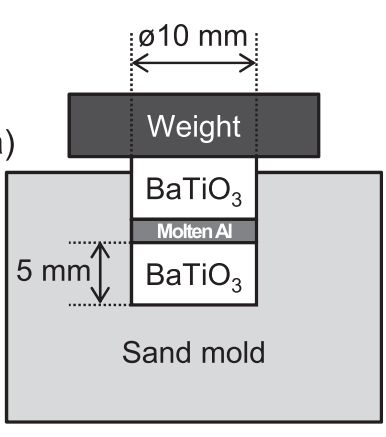

(b)

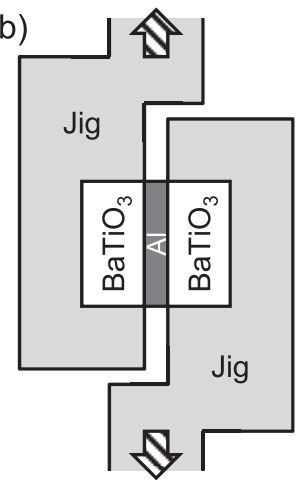

Fig. 1 Schematic illustrations of (a) joint specimen preparation and (b) shear testing.

Table 1 Joining conditions employed in this study.

\begin{tabular}{|c|c|c|}
\hline Temperature, $T /{ }^{\circ} \mathrm{C}$ & Pressure, $P / \mathrm{kPa}$ & Holding time, $t / \mathrm{h}$ \\
\hline \multirow{4}{*}{720} & \multirow{2}{*}{12.7} & 1.5 \\
\hline & & 3 \\
\hline & \multirow{2}{*}{25.4} & 1.5 \\
\hline & & 3 \\
\hline \multirow{8}{*}{780} & \multirow{6}{*}{12.7} & 1.5 \\
\hline & & 3 \\
\hline & & 10 \\
\hline & & 16 \\
\hline & & 24 \\
\hline & & 32 \\
\hline & \multirow{2}{*}{25.4} & 1.5 \\
\hline & & 3 \\
\hline
\end{tabular}

cut to obtain longitudinal cross-sections, which were polished using colloidal silica. The element distribution in the vicinity of the joint interface was analyzed using an electron probe micro analyzer (EPMA).

\section{Results and Discussion}

\subsection{Shear strength and aluminum layer thickness}

Figure 2 shows the relationships between the shear strength, aluminum layer thickness and joining conditions. For the specimens treated at temperatures of $720^{\circ} \mathrm{C}$, no joint strength was obtained as shown in Fig. 2(a). However, specimens heated to temperatures of $780^{\circ} \mathrm{C}$ had measurable shear strengths. All specimens exhibited interfacial delamination, suggesting that the measured shear strength reflects the joint strength. Specimens with holding times of $3 \mathrm{~h}$, had comparatively higher shear strengths. Differences in pressure also had small effects on shear strength and the aluminum layer thickness, as shown in Figs. 2(a) and 2(b), respectively. In general, higher temperature leads to better wettability ${ }^{10,14)}$, and higher pressure promotes a good contact ${ }^{14)}$. However, oxidation at higher temperatures and/or longer holding times sometimes negatively affected to the joint properties $^{3,14)}$. The results for another specimen treated at conditions of $780^{\circ} \mathrm{C}, 3 \mathrm{~h}$ and $12.7 \mathrm{kPa}$ with altered surface roughness on the $\mathrm{BaTiO}_{3}$ tablets, displayed extremely low shear strength with average values of $0.484 \mathrm{MPa}$ at $\mathrm{Ra} 1.4$ and $0.413 \mathrm{MPa}$ at $\mathrm{Ra}$ 3.0. These results reflect the tendency for higher surface roughness to cause poor joint quality, as well as insufficient contact with the molten aluminum ${ }^{9)}$. This also suggests that the molten aluminum and $\mathrm{BaTiO}_{3}$ treated at a
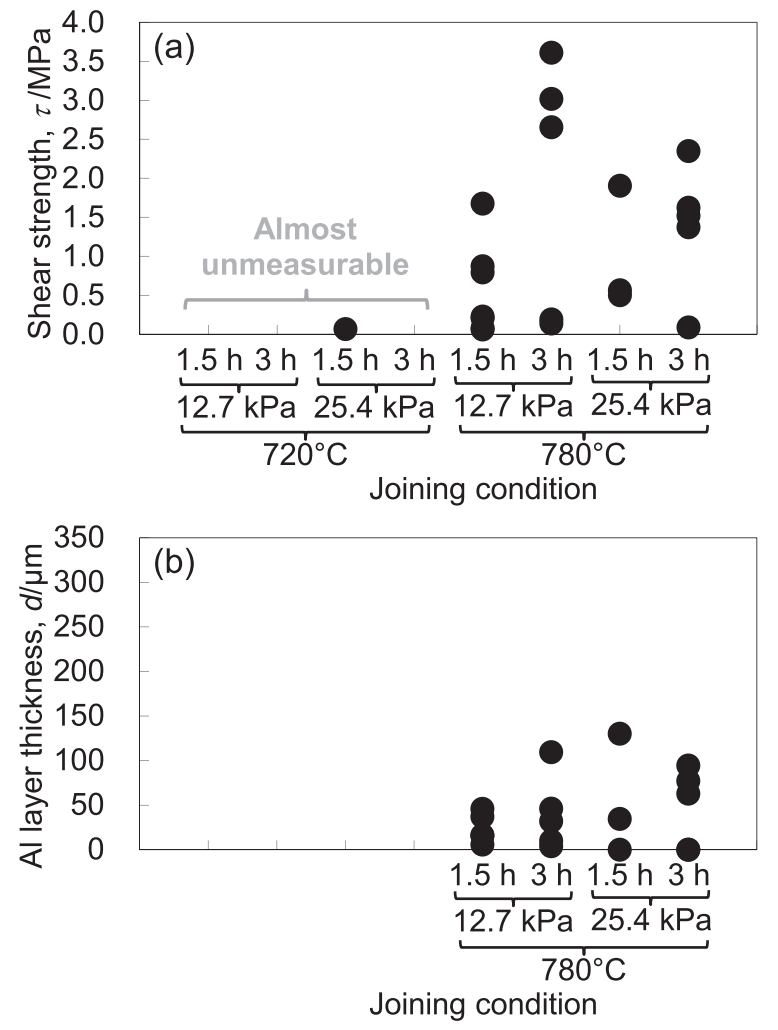

Fig. 2 Relationships between (a) shear strength and (b) aluminum layer thickness as a function of joining conditions. 
temperature of $780^{\circ} \mathrm{C}$ show the worst original wettability, with a contact angle of over $90^{\circ 9,18)}$. Hereafter, this study focused on joining conditions of $780^{\circ} \mathrm{C}$ and $12.7 \mathrm{kPa}$ without a change in the $\mathrm{BaTiO}_{3}$ surface roughness ( $\mathrm{Ra} 0.8$ ).

Figure 3 displays the relationships between the shear strength, aluminum layer thickness and holding time. As shown in Fig. 3(a), there is a tendency for the shear strength to increases with holding time. Lower shear strengths with interfacial delamination resulted for specimens treated with shorter holding times. In contrast, specimens treated with holding times of more than $16 \mathrm{~h}$ had higher shear strengths of more than $10 \mathrm{MPa}$. In particular, specimens with longer holding times (more than $24 \mathrm{~h}$ ) experienced fracture of the $\mathrm{BaTiO}_{3}$ along with the saturation of shear strength. This result suggests that the joint strength is greater than the shear strength of $\mathrm{BaTiO}_{3}$, despite requiring a more difficult joining method than cast-in insertion to obtain sufficient contact $^{2,6,7)}$. Although Fig. 3(a) also shows greater variability of the shear strengths for holding times of more than $24 \mathrm{~h}$, this implies that the variability depends on that of the strength of $\mathrm{BaTiO}_{3}$. Therefore, the fracture morphology changed with holding time, and practically enough joint strength was achieved through the braking at the base material $\left(\mathrm{BaTiO}_{3}\right)$. In addition, as shown in Fig. 3(b), there was a tendency for the aluminum layer thickness to gradually increase with holding time.

\subsection{Delaminated surface}

Figure 4 shows the appearances of the delaminated specimen surfaces for various holding times. As shown in
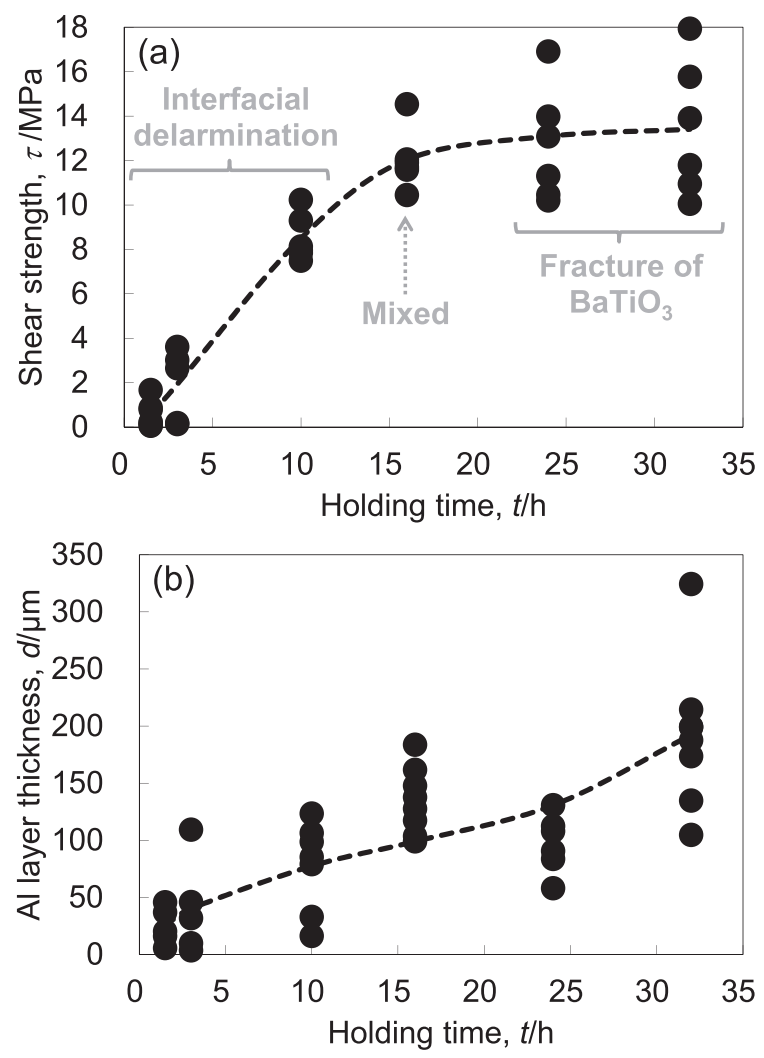

Fig. 3 Relationships between (a) shear strength and (b) aluminum layer thickness as a function of holding time (temperature: $780^{\circ} \mathrm{C}$, pressure: $12.7 \mathrm{kPa})$.
Figs. 4(a) and 4(c), glossy aluminum layers were observed on the delaminated surface for holding times of less than 10 h. In contrast, Figs. 4(e) and 4(g) display non-glossy aluminum layers that were observed on the surface for holding times of more than $16 \mathrm{~h}$. This finding implies the existence of $\alpha$-alumina $\left(\mathrm{Al}_{2} \mathrm{O}_{3}\right)$ that transformed from the $\gamma$-alumina passivation film that was originally presence on the glossy surface of the aluminum ${ }^{19)}$. In addition, adhesion of fractured $\mathrm{BaTiO}_{3}$ pieces to the aluminum layer near the joint periphery was observed in specimens with holding times of longer than 10 h, as shown in Figs. 4(c)-(h). This result suggests that the partial joint strength was higher near the joint periphery than near the center.

Figure 5 shows SEM images of the delaminated surface of the aluminum layer in specimens treated with various holding times. As shown in Figs. 5(a)-(f), less adhesion of the fractured $\mathrm{BaTiO}_{3}$ micro-grains was observed at the surface for holding times of less than $10 \mathrm{~h}$. In particular, the delaminated surface for a holding time of $1.5 \mathrm{~h}$ has very little mi-

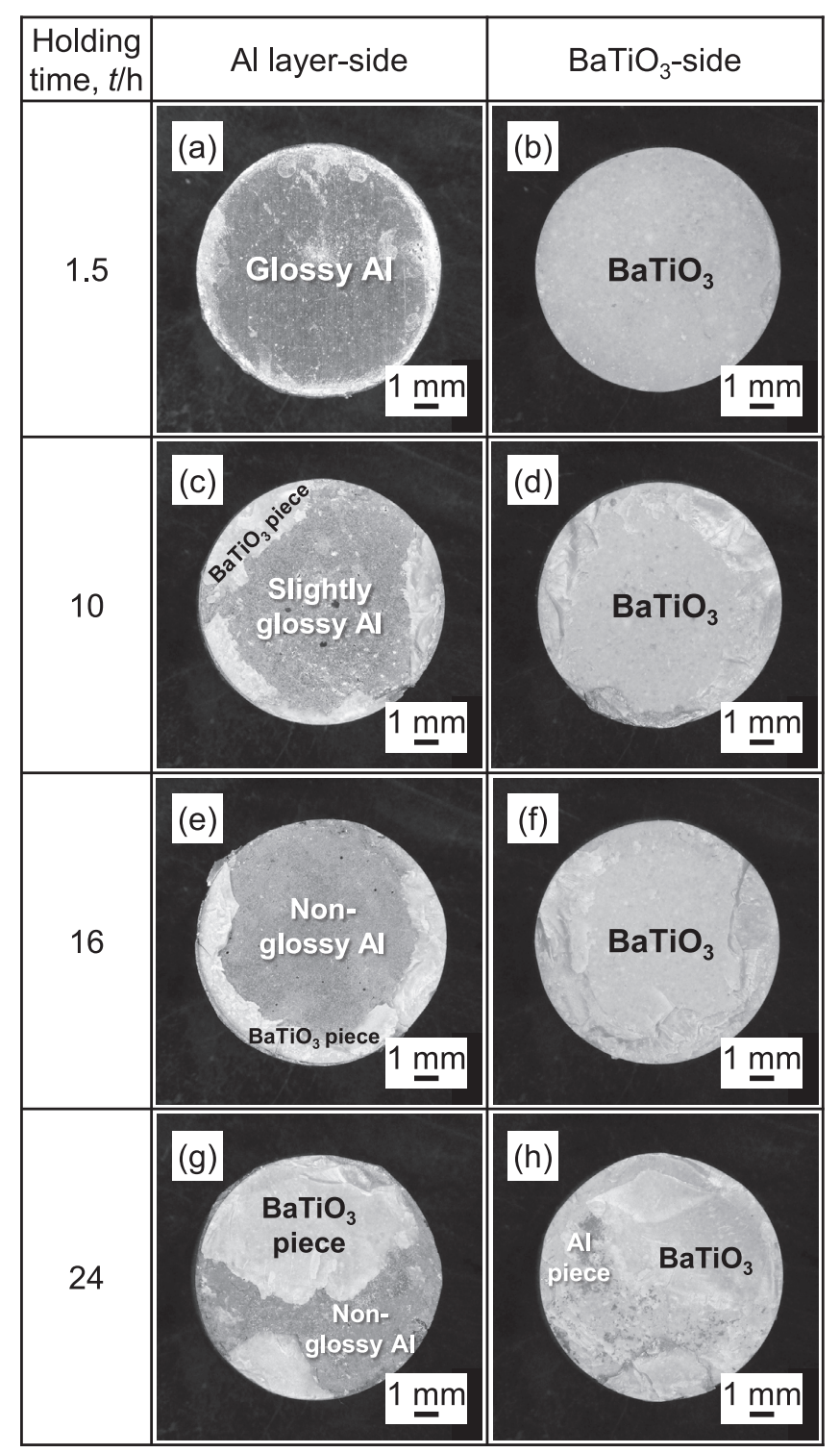

Fig. 4 Appearance of delaminated specimen surfaces (temperature: $780^{\circ} \mathrm{C}$, pressure: $12.7 \mathrm{kPa}$ ). 
cro-grain adhesion. On the other hand, considerable adhesion of large $\mathrm{BaTiO}_{3}$ grains at the surface occurred for a holding time of $16 \mathrm{~h}$ (Figs. 5(g) and 5(h)). In addition, the extent of adhesion was greater near the periphery than near the center. These results indicate that large locally bonded areas were produced by longer heat holding times, and that these areas also affect the overall shear strength of the specimens. This also means not only higher local joint shear strength near the periphery but also higher overall reliability against the difference of the thermal expansion, which is industrially useful ${ }^{2,14)}$.

\subsection{Element distributions}

Figure 6 shows an example of the cross-sectional element

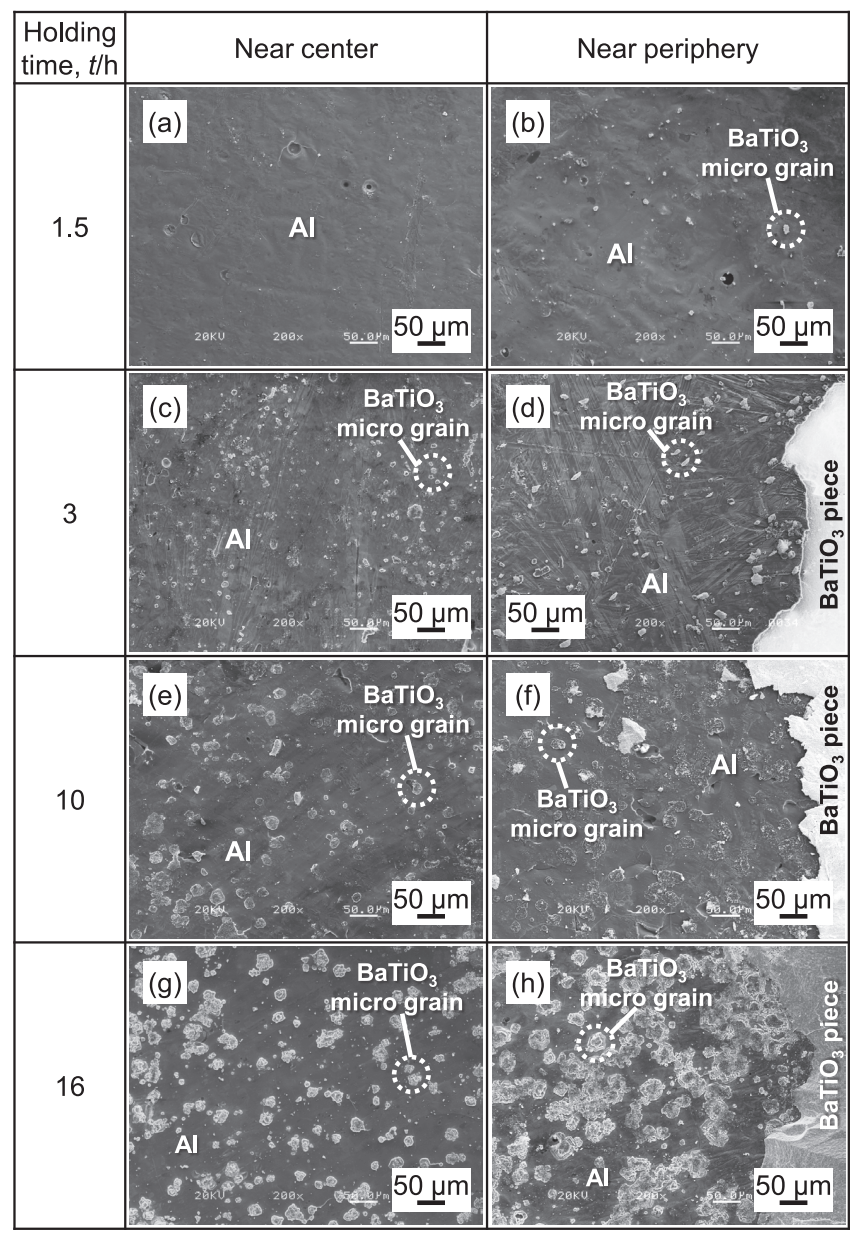

Fig. 5 SEM images of delaminated surface on aluminum layers from different specimens (temperature: $780^{\circ} \mathrm{C}$, pressure: $12.7 \mathrm{kPa}$ ). distribution in the vicinity of the joint interface near the periphery. This figure indicates that no interdiffusion of components such as titanium, aluminum, barium or oxygen occurred despite the long heat holding time of $32 \mathrm{~h}$. However, an oxygen-rich interlayer consisting of aluminum and oxygen was located between the $\mathrm{BaTiO}_{3}$ and the aluminum. This result indicates the presence of a relatively thick $\mathrm{Al}_{2} \mathrm{O}_{3}$ layer compared with the usual thickness of passivation films at the joint interface.

Figure 7 shows a comparison of the cross-sectional oxygen distribution in the vicinity of the joint interface in specimens treated with various holding times. The images in Figs. 7(c)-(f) confirm that oxygen-rich interlayers formed in specimens with holding times of more than $16 \mathrm{~h}$. In addition, less interlayer formation was observed near the center than near the periphery. However, in some poor-quality joints in specimen with a short holding time $(3 \mathrm{~h})$, no oxygen-rich interlayers were observed (Figs. 7(a) and 7(b)).

Figure 8 shows a typical microstructure and oxygen distribution of the delaminated surface in an aluminum layer near the periphery. Hexagonal areas were occasionally observed around the adhered $\mathrm{BaTiO}_{3}$ grains (Fig. 8(a)). In addition, as shown in Fig. 8(b), the hexagonal areas contained higher amounts of oxygen in the vicinity of the surface relative to the surrounding aluminum layer. These results imply that some kind of hexagonal single crystal growth of $\mathrm{Al}_{2} \mathrm{O}_{3}$ in a specific direction to the joint interface has occurred along with oxidation. Hexagonal $\alpha-\mathrm{Al}_{2} \mathrm{O}_{3}$ crystals such as corundum and sapphire are possible phases that may have formed $^{20)}$.

\subsection{Joining mechanism}

Figure 9 contains a schematic illustration of a plausible interfacial bonding mechanism. The above results suggest that both the transformation and growth of $\mathrm{Al}_{2} \mathrm{O}_{3}$ interlayers at higher temperatures and longer holding times increase the joint strength between $\mathrm{BaTiO}_{3}$ and aluminum (Fig. 9). Although the $\alpha-\mathrm{Al}_{2} \mathrm{O}_{3}$ phase is the stable structure at high temperature, transformation to $\alpha-\mathrm{Al}_{2} \mathrm{O}_{3}$ and growth are usually prevented by the presence of initial $\gamma-\mathrm{Al}_{2} \mathrm{O}_{3}$ passivation films ${ }^{19)}$. Nonetheless, progressive oxidation due to transformation cracking of $\mathrm{Al}_{2} \mathrm{O}_{3}$ at long holding times and high temperature have been reported ${ }^{19,21)}$. Oxidative volume expansion is one possible way for the thickness of the aluminum layer to increase, including the $\mathrm{Al}_{2} \mathrm{O}_{3}$ interlayers ${ }^{10)}$ (Fig. 3(b)), which may also promote cohesion. A number of reports address the bonding at the interface between $\alpha-\mathrm{Al}_{2} \mathrm{O}_{3}$ and aluminum ${ }^{10-12)}$. In addition, interfacial bonding

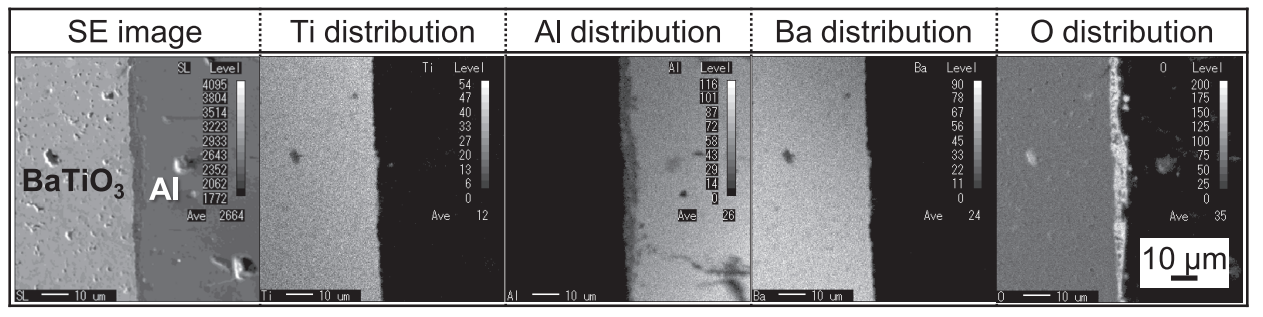

Fig. 6 Cross-sectional element distribution at the joint interface of various specimens near the periphery (temperature: $780^{\circ} \mathrm{C}$, pressure: $12.7 \mathrm{kPa}$, holding time: $32 \mathrm{~h})$. 


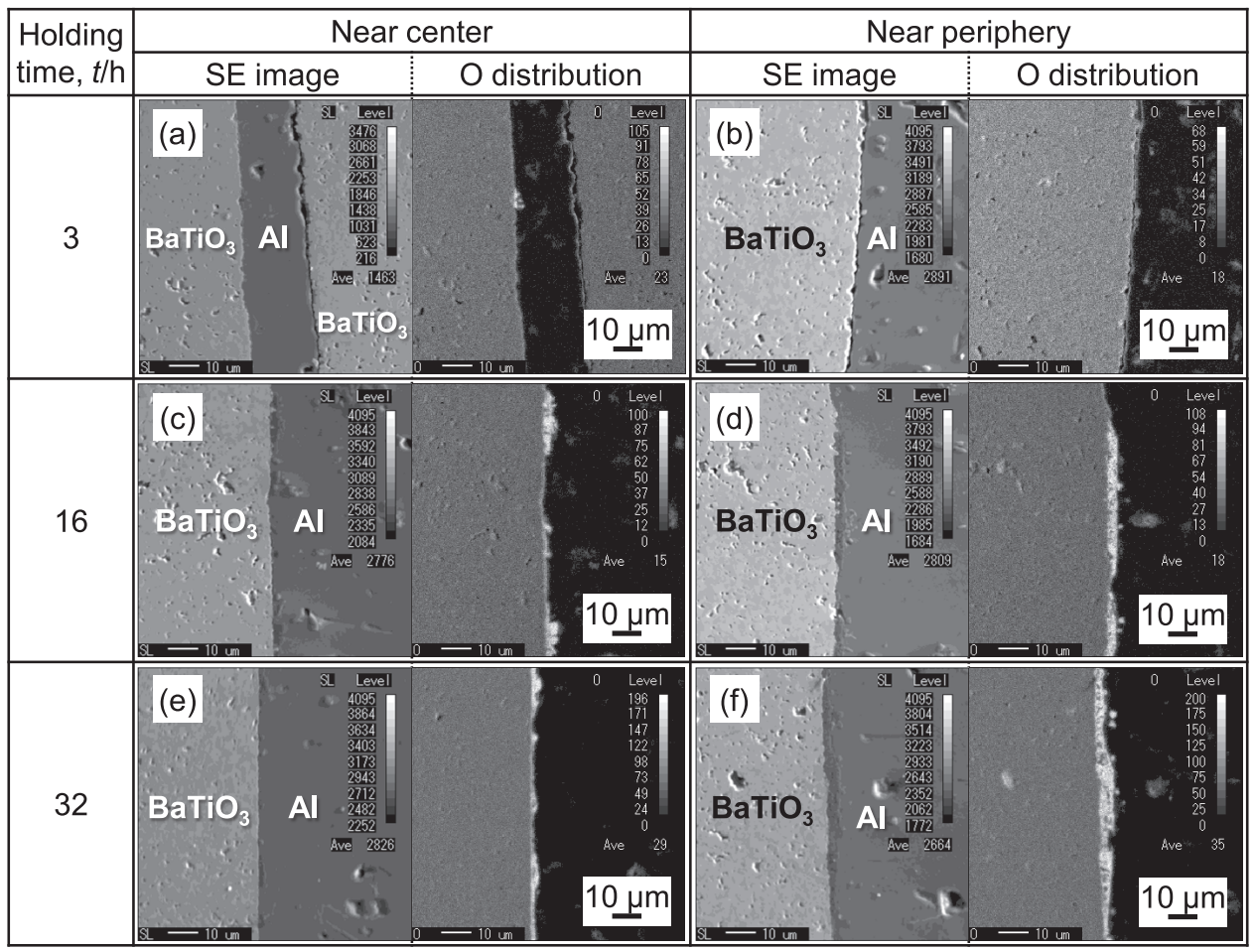

Fig. 7 Cross-sectional oxygen distribution in joint interface of various specimens (temperature: $780^{\circ} \mathrm{C}$, pressure: $12.7 \mathrm{kPa}$ ).
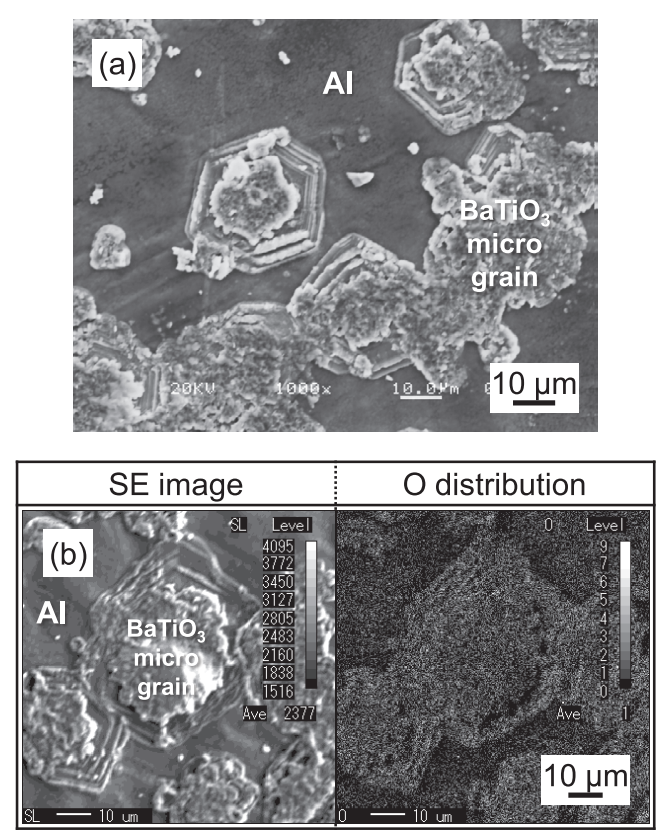

Fig. 8 (a) SEM image and (b) oxygen distribution of the delaminated surface on an aluminum layer near the periphery (temperature: $780^{\circ} \mathrm{C}$, pressure: $12.7 \mathrm{kPa}$, holding time: $16 \mathrm{~h}$ ).

between $\alpha-\mathrm{Al}_{2} \mathrm{O}_{3}$ and $\mathrm{BaTiO}_{3}$ may be achieved through a behavior similar to sintering because both phases are oxide ceramics. Sintering of $\mathrm{Al}_{2} \mathrm{O}_{3}$ and $\mathrm{BaTiO}_{3}$ is possible with the generation of certain other phases, such as $\mathrm{BaAl}_{13.2} \mathrm{O}_{20.8}$ and $\mathrm{BaAl}_{6} \mathrm{TiO}_{12}$, which exhibit fewer grain boundary fractures ${ }^{22,23)}$. These imply that the lattice matching of $\alpha-\mathrm{Al}_{2} \mathrm{O}_{3}$ with $\mathrm{BaTiO}_{3}$ or the certain other phases is higher than that of $\gamma-\mathrm{Al}_{2} \mathrm{O}_{3}$. The above aspects suggest that local bonding was achieved through the local transformation of $\alpha-\mathrm{Al}_{2} \mathrm{O}_{3}$ interlayers and expansion due to progressive oxidation, as shown in Fig. 9. Significant expansion of the bonded area near the periphery also suggests that the oxygen was supplied by the atmosphere. Therefore, this study indicates that joining of candidate PTC heaters will be possible by promoting oxidation during cast-in insertion despite the presence or absence of pressurization of the melt. On the basis of this study, for example, joining is likely to be rapidly achieved by the holding samples in an oxidative atmosphere and/or at much higher temperatures after pouring.

\section{Conclusions}

The effect of joining conditions on the joint strength of $\mathrm{BaTiO}_{3}$ brazed by molten aluminum was investigated along with the joining mechanism. The following conclusions were reached from the results of this study.

(1) High shear strengths of more than $10 \mathrm{MPa}$ that result in fracturing of $\mathrm{BaTiO}_{3}$ were obtained both with long holding times of more than $16 \mathrm{~h}$ and temperatures of $780^{\circ} \mathrm{C}$. Lower shear strengths with interfacial delamination resulted from shorter holding times. Shear strength was not adequately measurable for specimens treated at temperatures of $720^{\circ} \mathrm{C}$.

(2) Significant adhesion of fractured $\mathrm{BaTiO}_{3}$ pieces and grains to the aluminum layer was observed on delaminated surfaces resulting from longer heat holding times.

(3) The presence of a relatively thick $\mathrm{Al}_{2} \mathrm{O}_{3}$ layer between $\mathrm{BaTiO}_{3}$ and aluminum in the joint interface resulted from heat holding times of more than $16 \mathrm{~h}$.

(4) The above findings suggest that interfacial bonding is achieved through transformation of molten aluminum to 


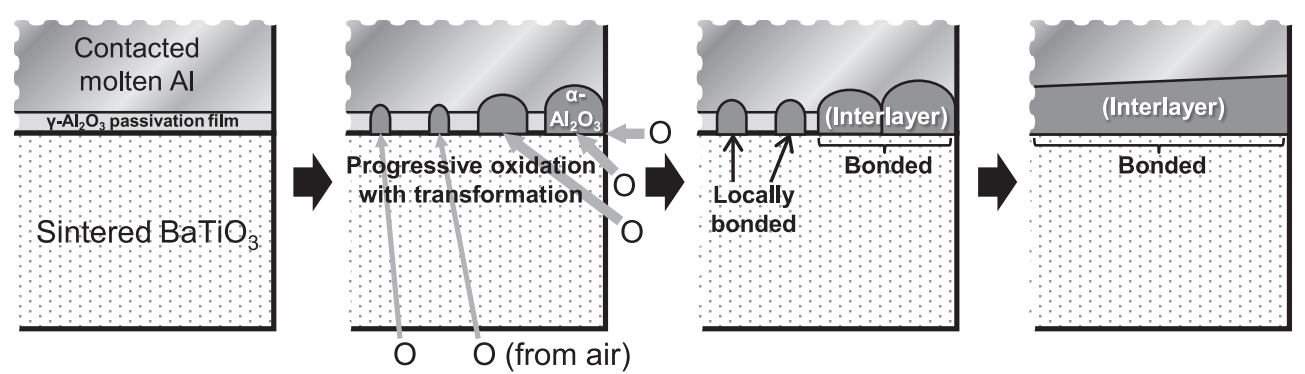

Fig. 9 Schematic illustration of the interfacial bonding mechanism produced with from long holding times and high temperatures.

an $\alpha-\mathrm{Al}_{2} \mathrm{O}_{3}$ interlayer due to progressive oxidation during joining.

\section{Acknowledgments}

This work was supported by the Japan Aluminium Association. The authors would like to thank Y.-G. So (Graduate School of Engineering Science, Akita University) for useful discussions.

\section{REFERENCES}

1) Air-Conditioning \& Refrigeration Systems Headquarters, Automotive Thermal Systems Department: Mitsubishi Heavy Industries Tech. Rev. 46 (2010) 19-21.

2) T. Takahashi, J. Nakamura, A. Sawabe, H. Osanai and A. Sugawara: J. MMIJ 124 (2008) 333-336

3) Y. Fukuzawa and Y. Kojima: JJILM 41 (1991) 660-666

4) I. Takahashi, T. Kuwashima, M. Kawahara and K. Kameta: Res. Bull. Iwate Industrial Research Institute 2 (1995) 57-61.

5) K. Suganuma: J. Mater. Sci. 26 (1991) 6144-6150.

6) H. Osanai: FC Report 28 (2010) 60-62.
7) I. Goto, K. Anzai and S. Ideguchi: Q. J. Jpn. Weld. Soc. 30 (2012) 345-353.

8) I. Goto: ALUMINIUM 20 (2013) 37-38.

9) K. Suganuma: J. Soc. Mater. Sci. Jpn. 44 (1995) 375-381.

10) K. Suganuma, E. Saiz and A.P. Tomsia: J. Jpn. Inst. Metals 62 (1998) 92-97.

11) E. Saiz, A.P. Tomsia and K. Suganuma: J. Eur. Cera. Soc. 23 (2003) 2787-2796.

12) J.Y. Kim and K.S. Weil: J. Am. Ceram. Soc. 90 (2007) 3830-3837.

13) A. Ibrahim and F. Hasan: J. Mater. Sci. Technol. 27 (2011) 641-646.

14) I. Goto, K. Anzai and S. Ideguchi: J. JFS 85 (2013) 76-83.

15) I. Goto and S. Aso: J. JFS 85 (2013) 745-752.

16) I. Goto and S. Aso: J. JFS 87 (2015) 109-116.

17) K. Otsuka, M. Tagami and A. Mutou: J. JFS 70 (1998) 891-896.

18) S. Sugihara, K. Okazaki, Y. Terashima and K. Kisamori: Jpn. J. Appl. Phys. 30 (1991) 2413-2415.

19) I. Haginoya and T. Fukusako: IMONO 54 (1982) 664-669.

20) M. Umehara: Ceram. Jpn. 42 (2007) 457-459.

21) E. Isoyama: Aluminum Finishing Society of Kinki 117 (1986) 1-6.

22) S. Rattanachan, Y. Miyashita and Y. Mutoh: J. Eur. Cera. Soc. 23 (2003) 1269-1276.

23) S. Rattanachan, Y. Miyashita and Y. Mutoh: J. Eur. Cera. Soc. 24 (2004) 775-783. 